\title{
Feedback em Ambientes Educacionais no Domínio de Programação
}

\author{
Priscylla Silva ${ }^{1,3}$, Evandro Costa $^{2}$, Joseana Régis de Araújo ${ }^{1}$ \\ ${ }^{1}$ Programa de Pós-Graduação em Ciência da Computação \\ Centro de Engenharia Elétrica e Informática \\ Universidade Federal de Campina Grande (UFCG) \\ ${ }^{2}$ Instituto de Computação - Universidade Federal de Alagoas (UFAL) \\ ${ }^{3}$ Instituto Federal de Alagoas - Campus Rio largo \\ priscylla.sousa@ifal.edu.br, evandro@ic.ufal.br, joseana@dsc.ufcg.edu.br
}

\section{Resumo}

O uso de ambientes de aprendizagem online - cujo objetivo é auxiliar no processo de ensino-aprendizagem - tem apresentado um rápido crescimento nos últimos anos. Um dos principais componentes que constituem esses ambientes é o feedback. Considerado um dos fatores mais significativos no processo de aprendizagem, o feedback é essencial para que o aluno obtenha um retorno sobre o seu desempenho e aprendizagem. Fornecer feedback aos estudantes em ambientes de aprendizagem online é um desafio, visto que diversos fatores e configurações devem ser levados em consideração ao se especificar um feedback, como questões de conteúdo, forma de apresentação e nível de personalização. Dentro desse contexto, nesta pesquisa são discutidos os desafios da criação de feedback voltados para ambientes educacionais no domínio de programação, em que os estudantes precisam praticar programação por meio da submissão de algoritmos que solucionem problemas. A maioria desses sistemas provê um feedback de baixa qualidade, informando ao estudante apenas se sua solução está correta ou não. Muitos estudantes não conseguem, a partir desse simples feedback, progredir em seu aprendizado. Nessa perspectiva, esta pesquisa propõe uma abordagem para auxiliar estudantes durante a utilização de um sistema tutor de programação por meio do provimento de auxílio no processo de resolução de exercícios de codificação, fornecendo mensagens de feedback contendo dicas para a correção de erros e como proceder em seus próximos passos para completar a solução. Com a abordagem proposta, o estudante não precisa completar e submeter uma solução para receber um textiffeedback. A proposta utiliza três recursos de feedback: fluxogramas, vídeos e dicas em formato de texto. Nós conduzimos um quase-experimento envolvendo 34 estudantes de uma disciplina introdutória de programação. Os resultados indicaram que a abordagem proposta obteve um impacto positivo na aprendizagem dos estudantes. Nossos resultados também sugerem que a abordagem consegue fornecer mensagens de $f e$ edback úteis aos estudantes com dificuldades em concluir uma solução [Silva et al. 2019].

\section{Referências}

Silva, P., Costa, E., and de Araújo, J. R. (2019). An adaptive approach to provide feedback for students in programming problem solving. In Coy, A., Hayashi, Y., and Chang, M., editors, Intelligent Tutoring Systems, pages 14-23, Cham. Springer International Publishing. 